\title{
Electrical Signs of Selective Attention in the Human Brain
}

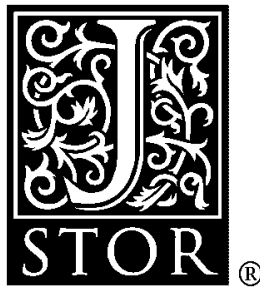

\author{
Steven A. Hillyard; Robert F. Hink; Vincent L. Schwent; Terence W. Picton
}

Science, New Series, Vol. 182, No. 4108. (Oct. 12, 1973), pp. 177-180.

Stable URL:

http://links.jstor.org/sici?sici=0036-8075\%2819731012\%293\%3A182\%3A4108\%3C177\%3AESOSAI\%3E2.0.CO\%3B2-3

Science is currently published by American Association for the Advancement of Science.

Your use of the JSTOR archive indicates your acceptance of JSTOR's Terms and Conditions of Use, available at

http://www.jstor.org/about/terms.html. JSTOR's Terms and Conditions of Use provides, in part, that unless you have obtained prior permission, you may not download an entire issue of a journal or multiple copies of articles, and you may use content in the JSTOR archive only for your personal, non-commercial use.

Please contact the publisher regarding any further use of this work. Publisher contact information may be obtained at http://www.jstor.org/journals/aaas.html.

Each copy of any part of a JSTOR transmission must contain the same copyright notice that appears on the screen or printed page of such transmission.

The JSTOR Archive is a trusted digital repository providing for long-term preservation and access to leading academic journals and scholarly literature from around the world. The Archive is supported by libraries, scholarly societies, publishers, and foundations. It is an initiative of JSTOR, a not-for-profit organization with a mission to help the scholarly community take advantage of advances in technology. For more information regarding JSTOR, please contact support@ jstor.org. 
from baseline cardiovascular levels under the same general laboratory conditions obtaining for the four baboons which provide the basis for this report.

The results of this experiment show clearly that instrumental learning of cardiovascular responses can produce sustained large-magnitude changes in blood pressure which cannot be accounted for on the basis of short-term "voluntary mediators" (for example, the Valsalva maneuver) (3). All four baboons in this study showed daily elevations of $30 \mathrm{~mm}-\mathrm{Hg}$ or more in both systolic and diastolic blood pressures and maintained such elevations for the entire 12-hour conditioning-on segment of each experimental session. These findings suggest the involvement of more durable adaptive mechanisms supporting the sustained pressure elevations, although the relative contributions of cardiac output and peripheral resistance to the establishment and maintenance of these hypertensive levels cannot be determined from the present data alone. In dogs anticipating (over a 15-hour interval) performance on a shock-avoidance procedure $(1,3)$, and in rhesus monkeys during a 72-hour shock-avoidance procedure (14), similar blood pressure elevations have been reported, and concurrent measurements of cardiac output under such conditions (15) have revealed that the pressure elevations were determined by substantial increases in total peripheral resistance. Although the relationship of these sustained blood pressure elevations in the baboon to the circulatory changes characteristic of essential hypertension in humans (16) is far from clear, chronic exposure to aversive behavioral conditioning procedures has been reported to produce hypertensive patterns (17), with a bradycardia accompanying the chronic pressure elevations in at least some animals (18). The present findings with the baboon extend the range of potentially useful laboratory models for the analysis of environmental-behavioral influences upon the cardiovascular system, and call for further experimental scrutiny of the physiological mechanisms (for example, baroreceptor reflex) which mediate this significant alteration of the systemic circulation.

alan H. Harris, Willie J. Gilliam

JACK D. FINDLEY, JOSEPH V. BRADY Department of Psychiatry and Behavioral Sciences, Johns Hopkins. University School of Medicine,

Baltimore, Maryland 21205
References and Notes

1. V. DiCara and N. E. Miller, Psychosom. Med. 30, 489 (1968).

2. H. Benson, J. A Herd, W. H. Morse, R. T Kelleher, Amer. J. Physiol. 217, 30 (1969). 3. L. A. Plumlee, Psychophysiology 4, 507 (1968).

4. A. H. Harris, J. D. Findley, J. V. Brady, Conditional Reflex 6, 215 (1971).

5. J. Brener and R. A. Kleinman, Nature 226 , 1063 (1970); H. Benson, D. Shapiro, B. Tursky, G. E. Schwartz, Science 173, 740 (1971).

6. D. Shapiro, B. Tursky, E. Gershon, M. Stern, Science 163, 588 (1969); D. Shapiro, B. Tursky, G. E. Schwartz, Psychosom. Med. 32 417 (1970); Circ Res. 26 (Suppl. 1) 27 (1970); G. Schwart. 26 (Suppl. 1), 27 (1970); G. E. Schwartz, D. Shapiro, B. Tursky, Psychosom. Med. 33, 57 (1971); G. E. Schwartz, Science 175, 90 (1972); D. Shapiro, G. E. Schwartz, B. Tursky, Psychophysiology 296 (1972).

7. E. S. Katkin and E. N. Murray, Psychol. Bull. 70, 52 (1968); A. Crider, G. Schwartz, S. Shnidman, ibid. 71, 455 (1969); E. S Katkin, E. N. Murray, R. Lachman, ibid., p. 462.

8. J. D. Findley, W. W. Robinson, W. J. Gilliam, J. Exp. Anal. Behav. 15, 69 (1971). 9. J. Perez-Cruet, L. Plumlee, J. E. Newton,
Proc. Symp. Bio-Med. Eng. 1, 383 (1966);

D. Werdegar, D. G. Johnson, J. W. Mason, J. Appl. Physiol. 19, 519 (1964).

10. A De La Pena and J. W. Goldzieher in The Baboon in Medical Research, Proceedings of Baboon in Medical Research, Proceedings of the Second International Symposium on the Baboon and Its Uses as an Experimenta Animal, H. Vagtborg, Ed. (Univ. of Texas Press, Austin, 1965), vol. 2, p. 379.

11. J. D. Findley, J. V. Brady, W. W. Robinson, W. J. Gilliam, Commun. Behav. Biol. 6, 49 (1971).

12. M. E. T. Swinnen, Proc. Annu. Conf. Eng. Med. Biol. 10, 18.4 (1968).

3. D. E. Anderson and J. V. Brady, Psychosom. Med. 35, 4 (1973).

14. R. P. Forsyth, Science 173, 546 (1971).

15. D. E. Anderson and J. Tosheff, J. Appl. Physiol. 34, 650 (1973).

16. I. Page and J. W. McCubbin, in Handbook of Physiology, W. F. Hamilton, Ed. (American Physiological Soc., Washington, D.C. 1965), section 2, Circulation, vol. 3, pp. 21631965),

17. J. A. Herd, W. H. Morse, R. T. Kelleher L. G. Jones, Amer. J. Physiol. 217, 24 (1969).

18. R. P. Forsyth, Psychosom. Med. 31, 300 (1969).

19. Supported by NIH grant HE-06945 and ONR subcontract N0014-70-C-0350.

5 June 1973

\section{Electrical Signs of Selective Attention in the Human Brain}

Abstract. Auditory evoked potentials were recorded from the vertex of subjects who listened selectively to a series of tone pips in one ear and ignored concurrent tone pips in the other ear. The negative component of the evoked potential peaking at 80 to 110 milliseconds was substantially larger for the attended tones. This negative component indexed a stimulus set mode of selective attention toward the tone pips in one ear. A late positive component peaking at 250 to 400 milliseconds reflected the response set established to recognize infrequent, higher pitched tone pips in the attended series.

Human listeners are able to confine their attention to a single auditory message within a noisy environment and to disregard equally intense but "irrelevant" sounds. This feat of selective attention is accomplished by unknown brain mechanisms that act both to enhance the information received from selected sound sources and to suppress irrelevant, competing sensory input.

Attempts to identify neurophysiological mechanisms that uniquely subserve selective attention by recording sensory evoked potentials from animal brains have made little progress $(1,2)$. Human subjects offer distinct advantages in that their attentional processes can be accurately controlled and evaluated in conjunction with sensory evoked potentials that are recorded from the scalp. It is well established that the major components of the human auditory evoked potential-a negative component $\left(\mathrm{N}_{1}\right)$ peaking at 80 to 110 msec after an abrupt sound and a subsequent positive component $\left(\mathrm{P}_{2}\right)$ at 160 to $200 \mathrm{msec}$-are considerably larger when the sound is made "relevant" (to be attended) than when it is made "irrelevant" (to be ignored) (3).
Naatanen (2) has pointed out, however, that relevant stimuli were delivered predictably in those studies, so that the effects of stimulus "relevance" upon evoked potentials could have been caused by nonselective preparatory states (for example, arousal or alertness) differentially preceding the stimuli. In experiments where the relevant and irrelevant stimuli were presented in randomized sequences that precluded differential preparatory states $(2,4,5)$, only minimal differences were observed in $\mathrm{N}_{1}$ and $\mathrm{P}_{2}$.

We now report experiments in which randomized sequences of tone pips were delivered concurrently to the two ears at such a rapid rate that subjects were forced to restrict their attention to one ear at a time in order to perform a difficult pitch discrimination. Under these circumstances the $\mathrm{N}_{1}$ evoked by tones in the attended ear was substantially larger than that evoked by tones in the opposite ear. This constitutes the first definite evidence that changes in an evoked potential component can specifically reflect selective attention as opposed to a preparatory or reactive change of nonselective state $(6,7)$.

Subjects sat in an acoustically shielded 
chamber while binaural sequences of tone pips were presented through stereo earphones. In experiment 1 , a sequence of $800-\mathrm{hz}$ tone pips ( $50 \mathrm{db}$ above threshold, 50-msec duration) with interstimulus intervals randomized between 250 and $1250 \mathrm{msec}$ was delivered to the left ear, while an independent series of $1500-\mathrm{hz}$ tone pips of similar intensity, duration, and random intervals was presented to the right ear. These concurrent binaural sequences each consisted of 512 tone pips that had been recorded earlier on an audio tape which ran for 6 minutes. About one-tenth of the tone pips in each ear had a somewhat higher frequency than the "standard" 800- and 1500-hz tone pips: the frequencies of these "signals" were 840 $\mathrm{hz}$ (left ear) and $1560 \mathrm{hz}$ (right ear). These signals were interposed every 3 to 20 stimuli at random throughout each sequence.

The same stimulus tape was played to the subject six times in succession with a 5-minute break after each.

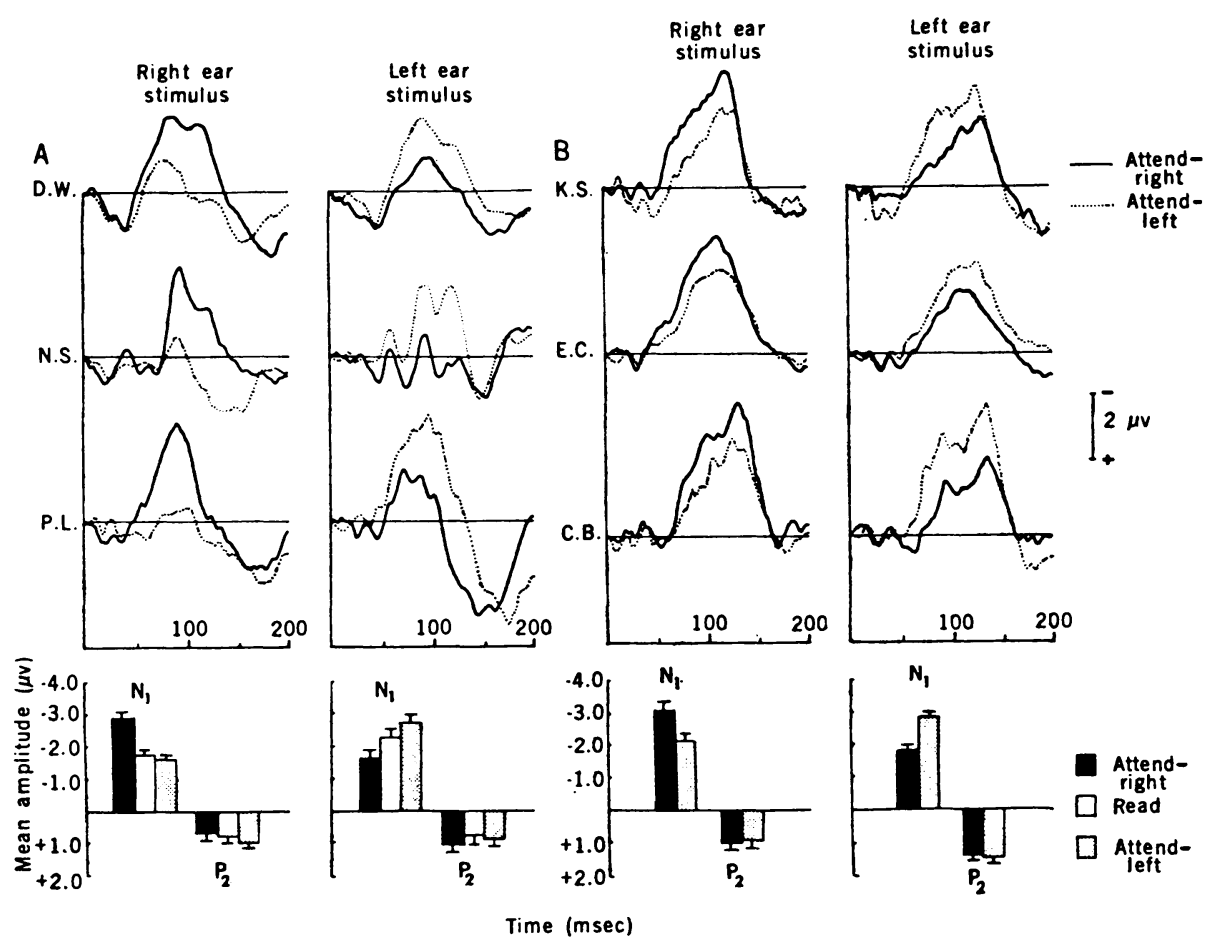

Fig. 1. (A) Vertex evoked potentials from three subjects in experiment 1. Each tracing is the averaged response to all 1024 stimuli that were presented to each ear under attend-right (solid lines) and attend-left (dotted lines) conditions. Stimulus onset is at beginning of tracing. Baselines were drawn through the mean voltage over 0 to $10 \mathrm{msec}$. Bar graphs give the mean and standard error (10 subjects) of the baseline to peak amplitudes of $\mathrm{N}_{1}$ and $\mathbf{P}_{2}$ evoked via each ear under all three experimental conditions. (B) Evoked potentials from three subjects in experiment 2, with bar graphs giving mean amplitudes over all ten subjects.

Fig. 2. The $\mathbf{P}_{3}$ component (shaded area) evoked by signal tone pips in the attended ear. The $P_{3}$ is absent in the evoked potential to the standard tone pips (solid tracings). Each tracing is the averaged response to 90 to 110 stimuli; the standard tones were selected at random from throughout the stimulus sequence. The data are from three subjects during both experiment 1 (D.W. and P.L.) and experiment 2 (N.S.).

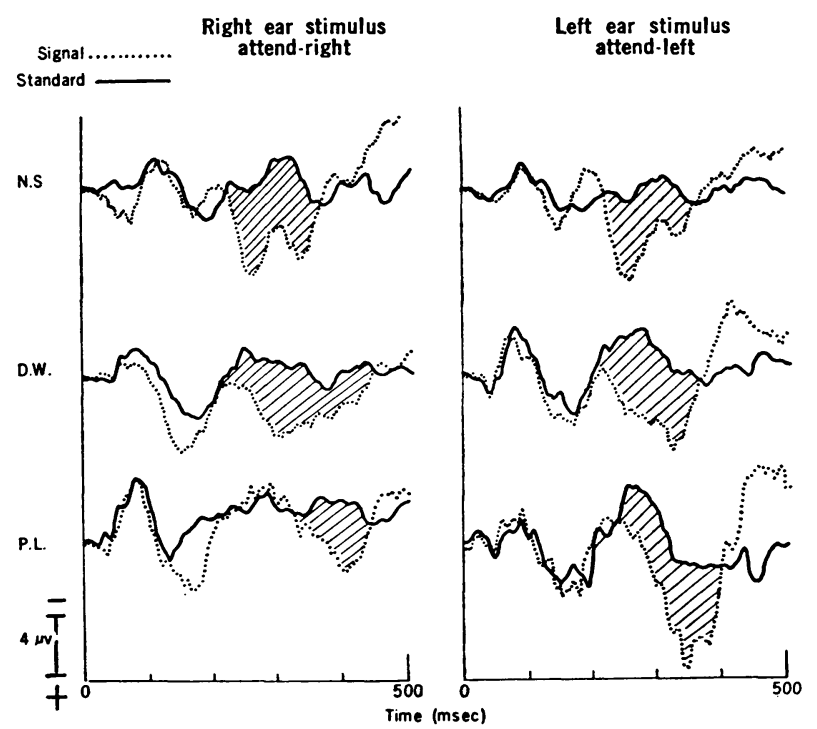

There were three instructional conditions as follows: A, attend to the left ear, discriminate and count the number of $840-\mathrm{hz}$ signals, and report the total at the end of the run; $B$, read a novel and disregard all tones; $C$, attend to the right ear and count the number of $1560-\mathrm{hz}$ tones. Hereafter we refer to condition A as "attend-left" and condition C as "attend-right." Five young adult subjects received the instructional conditions in ABCCBA order and five others in CBAABC order. The reading condition was used to reduce carry-over effects between successive attend-left and attend-right conditions.

Evoked potentials to all stimuli were recorded from the vertex (mastoid reference) with the use of Grass amplifiers (model 6) (bandpass 1 to $70 \mathrm{hz}$ ) and stored on FM tape for off-line analysis on a sıgnal averager (Fabritek 1052). Evoked vertex potentials to left and right ear stimuli were averaged separately across all 1024 tone pips (standaras and signals) of an instructional condition (8). Electrical potentials caused by eye movements and blinks were recorded between electrodes above and below the left eye to ensure that evoked potentials were Iree of ocular artifacts.

In the left column of Fig. 1A, the $\mathrm{N}_{1}$ evoked by right ear tones was considerably larger when those stimuli were attended (solid tracings) than when the left ear tones were receiving attention (dotted tracings); conversely, in the right column of Fig. 1A, larger $\mathrm{N}_{1}$ 's were evoked by left ear tones during the attend-left condition (dotted tracings) than during the attend-right runs (solid tracings). These effects were observed in every subject. The amplitude of $\mathrm{N}_{1}$ evoked by right ear tones (measured baseline to peak) was between 20 and 75 percent smaller during the attend-left as compared with the attend-right condition [mean difference $=43.5$ percent; $t(9)=7.88 ; P<$ $10^{-4}$ (two-tailed)]; conversely, the $\mathrm{N}_{1}$ evoked by the concurrent left ear sequence was between 22 and 78 percent smaller under attend-right conditions than under attend-left [mean $=38.9$ percent; $t(9)=7.28 ; P<10^{-4}$ ]. Thus, when attention was switched from one ear to the other, the reciprocal effects of selective attention-suppression of $\mathrm{N}_{1}$ evoked by tones in the unattended ear and enhancement of $\mathrm{N}_{1}$ evoked in the attended ear-were approximately symmetrical.

These manipulations produced a clear dissociation between $\mathrm{N}_{1}$, which was an index of the direction of atten- 
tion, and $\mathbf{P}_{2}$, which was not significantly altered in either ear (Fig. 1). The effects of attention upon $\mathrm{N}_{1}$ could not have been caused by any sustained change of nonselective state. It is conceivable, however, that very rapid fluctuations of some nonselective preparatory state might have become partially time locked to the schedule of tones in the attended ear. If such hypothetical changes of state increased all evoked potentials nonselectively, those of the attended ear would be preferentially enhanced because its stimulus schedule would be more closely coupled to the cycles of preparatory state.

To rule out these effects a second experiment was carried out in which tone pips were delivered to right and left ears according to a single sequence rather than two independent overlapping sequences as in experiment 1 . Within this sequence the time intervals between successive tones were randomized between 100 and $800 \mathrm{msec}$, and each tone was delivered either to the right $(800 \mathrm{hz})$ or left $(1500 \mathrm{hz})$ ear with equal probability. Experiment 2 was otherwise identical to experiment 1 except for omission of the reading condition. Of the ten subjects used in experiment 2 , eight participated in the previous experiment.

The results of experiment 2 paralleled those of experiment 1 (Fig. 1B). The amplitude of $N_{1}$ evoked by right ear tones was between 10 and 68 percent smaller under the attend-left condition than under the attend-right condition [mean $=30.1$ percent; $t(9)=$ 5.05; $P<10^{-3}$ ]; conversely, $\mathrm{N}_{1}$ evoked by left ear tones was 15 to 69 percent smaller when attention was shifted from the left to the right ear [mean $=$ 34.0 percent; $t(9)=7.31 ; P<10^{-4}$ ]. These reciprocal effects of selective attention were on the average less than in the first experiment. Most subjects reported greater difficulty in keeping their attention on one ear when the binaural stimulus schedule was sequential, and this difficulty could explain the reduced effect. Therefore, we obtained no evidence for the thesis that cycles of nonselective alertness can exert a differential effect upon $\mathrm{N}_{1}$ in the two ears over and above the dominant factor of selective attention.

The vertex potentials evoked by the occasional higher pitched signals in the attended ear were examined separately on a $500-\mathrm{msec}$ time base. A late positive component peaking at 250 to 400 msec, $P_{3}$ (Fig. 2, shaded area), was elicited only after the signal tones and not by the standard tones ( 9 ).
Three features were incorporated into the present experiments which together distinguish them from earlier studies $(4,5)$ which did not reveal any substantial effect of selective attention upon $\mathrm{N}_{1}$. First, the relevant and irrelevant stimuli differed from one another both in spatial localization and pitch attributes. This made them easily distinguishable. Second, the stimuli were delivered at such a high rate that it was impossible to discriminate stimuli in one ear and fully appreciate the stimuli to the other ear at the same time (10). Finally, the frequency discrimination tasks were difficult. Subjects reported hearing at most only a few of the signals in the unattended ear (11).

The early latency of the attention effects upon $N_{1}$ (evident at 60 to 70 msec in most subjects) suggests that the underlying attentional process is a tonically maintained set favoring one ear over the other rather than an active discrimination and recognition of each individual stimulus. Furthermore, if $\mathrm{N}_{1}$ was enhanced after the differential recognition of relevant stimuli or a subsequent "reactive change of state" (6), an equivalent or larger $\mathrm{N}_{1}$ should have occurred in the previous experiments $(4,5)$ having slower rates of stimulus presentation. The $\mathrm{P}_{3}$, on the other hand, does seem to be elicited only upon the recognition of selected signals which require a special cognitive or motor response (12).

Our results suggest that $\mathrm{N}_{1}$ and $\mathbf{P}_{3}$ are signs of fundamentally different selective attention processes, corresponding closely to the "stimulus set" and "response set" modes of attention, respectively, described by Broadbent (13) and others (14). A stimulus set preferentially admits all sensory input to an attended channel (stimuli having in common a simple sensory attribute such as pitch, position in space, receptor surface, or the like) for further perceptual analysis, while blocking or attenuating inputs arriving over irrelevant channels (for example, the unattended ear) at an early stage of processing. Response set is a subsequent processing stage in which sensory information as compared against memorized "templates" or "models" (7) for selected stimuli which are not distinguishable simply by virtue of belonging to: a particular sensory input channel; a response set acts to facilitate the recognition of these specific task-relevant signals.

These two hierarchical modes of attention generally operate together. At a cocktail party, for example, it is necessary to establish a stimulus set in favor of the location and pitch characteristics of a speaker's voice, and a succession of response sets to recognize the specific contents of his speech. In the present experiment we propose that the amplitude of $\mathrm{N}_{1}$ indexes the stimulus set which selectively excludes sensory input to the unattended ear from further processing. The $\mathrm{P}_{3}$, on the other hand, reflects the selective recognition of the higher pitched tones in the attended channel by a response set mechanism which is coupled with an appropriate cognitive response (counting) (16).

Steven A. Hillyard, Robert F. Hink VINCENT L. SCHWENT Terence W. Picton

Department of Neurosciences, University of California, San Diego, La Jolla 92037

\section{References and Notes}

1. While animal studies permit the localization of neurophysiological events to specific brain structures, the control and evaluation of selective attention as distinct from general arousal and alertness is most difficult [R. F. Thompon and $\mathrm{L}$. A . B Thompson and $\mathrm{L}$. A. Bettinger, in Attention: Mostofsky, Ed. (Appleton-Century-Crofts, New Mostofsky, Ed. (Applet

2. R. Naatanen, Ann. Acad. Sci. Fenn. Ser. B 151, 1 (1967).

H. Davis, Science 145, 182 (1964); P. Spong M. Haider, D. B. Lindsley, ibid. 148, 395 (1965); M. M. Gross, H. Begleiter, M. Tobin, B. Kissin, Electroencephalog. Clin. Neurophysiol. 18, 451 (1965); J. H. Satterfield, ibid., p. 470 ; R. T. Wilkinson and H. C. Morlock, ibid. 23, 50 (1967); S. K. Hirsch, Psychon. Sci. 22, 173 (1971); L. Keating and H. Ruhm, Audiology 10, 177 (1971); T. W. Picton, S. A. Hillyard, R. Galambos, M. Schiff, Science 173, 351 (1971).

4. L. R. Hartley, Quart. J. Exp. Psychol. 22 531 (1970); D. Smith, E. Donchin, L. Cohen, A. Star, Electroencephalog. Clin. NeuroA. Star, Electroencephal
physiol. 28, 146 (1970).

5. R. T. Wilkinson and M. V. Lee, Electroencephalog. Clin. Neurophysiol. 33, 411 (1972) Stimulus relevance has been shown to in . Stimulus relevance has been shown to inmsec in numerous experiments which controlled for possible anticipatory arousal effects. For overview see: Wilkinson and Lee (5) and Squires et al. (7). While such change in long latency components (most evident in a positive wave, $\mathrm{P}_{3}$, peaking at 250 to 400 msec) are clearly dependent upon a stimulus recognition process, it is possible that these late waves are signs of a nonselective reactive change of state which follows recognition of the signals [L. Karlin, Psychol. Bull 73, of the signals [L. Karlin, Psychol. Bull. 73 122 (1969)]. Recently, J. Ford, W. Roth, S Dirks, B. Kopell [Science 181, 465 (1973)] reported a dissociation between the $\mathrm{N}_{2}$ (laency 190 to $270 \mathrm{msec})$ and $\mathrm{P}_{3}(270$ to 500 $\mathrm{msec}$ ) components during an auditory an visual selective attention task. $\mathbf{N}_{2}$ was equally enhanced for all stimuli (target and nontarget) within the attended modality, while $\mathrm{P}_{3}$ was largest following the targets. Whether such late changes reflect selective gating of inputs or nonselective aftereffects of stimulus discrimination and recognition is still an open question

7. K. Squires, S. Hillyard, P. Lindsay, Percept. Psychophys. 13, 25 (1973)

8. As a precaution, evoked potentials were also averaged across the standard stimuli in each ear, excluding the higher-pitched signals These averages showed similar selective at These averages showed similar selective attention effects upon $\mathbf{N}_{1}$ as did the averages across all stimuli. This ensures that a long term nonspecific arousal process, rising to a maximum prior to a signal and falling thereafter, did not differentially bias the evoke 
9. In all subjects the largest $P_{3}$ waves were evoked after the signals in the attended ear. In several subjects a smaller $P$. In several subjects a smaller $\mathrm{P}_{3}$ was sometimes evident following the signals in the from the unattendicating that information from the unattended ear was occasionally being examined. No. $\mathrm{P}_{3}$ was discernible afte the standard tones in either ear. As Fig. indicates, the difference between the $\mathrm{N}$ tones was not substantial.

10. The mean interstimulus interval (for both ears together) was $375 \mathrm{msec}$ in experiment and $450 \mathrm{msec}$ in experiment 2 . Wilkinson and Lee (5) also delivered stimuli (one of three tone frequencies) at a rapid rate (mean tone frequencies) at a rapid rate (mean interval $=673$ msec) with the aim of forcin subjects to ignore that counting a stimulus enhanced the $\mathrm{N}_{1}-\mathrm{P}$ The authors attribute this effect to augmenting of $\mathrm{P}_{2}$ by a positive $\mathrm{d}-\mathrm{c}$ baseline shift rathe than to selective attention. No independen effect upon $\mathrm{N}_{1}$ was reported.

11. The overall percentages of the signal tones detected had the following medians $(M)$ and interquartile ranges (R). Experiment 1 , left ear $(M, 90 ; R, 84$ to 96$)$; and right ear (M, $90, \mathrm{R}, 84 \mathrm{to}, \mathrm{R})$, and right ear (M, 81 $R$, 70 to 92). Experiment 2, left ear (M, 88; $\mathrm{R}, 82$ to 94 ); and right ear (M, 94; R, 90 to

2. The $P_{3}$ wave (often preceded by a negative wave at $200 \mathrm{msec}$ ) is elicited upon the detection of many types of auditory and visua signals (7). A study by R. Eason, M. Harter, is a visual analog of our experiment with stimuli being presented to the two halves of the visual field rather than to the two ears. evoked by standard as compared to signal component by about 10 percent $(P<.05)$ and C. White [Physiol. Behav. 4, 283 (1969)]
Stimuli in the attended field evoked large waves of long latency (beyond $150 \mathrm{msec}$ ) (which include $P$ ) instead of a tonic set favoring the attended field. Theory and Analysis, D. I. Mostofsky, Ed. Theory and Analysis, D. I. Mostofsky, Ed.
(Appleton-Century-Crofts, New York, 1970), p. 51 .

14. The stimulus set and response set distinction has been posed in various terms by different theorists, for example: attention and abstraction [D. E. Berlyne, in Attention: Contemporary Theory and Analysis, D. I. Mostofsky, Ed. (Appleton-Century-Crofts, New York, 1970), p. 25]; input selection and target selection [A. M. Treisman, Psychol. Rev. 76, 282 (1969)]; filter and template [F. G. Worden and R. Galambos, Neurosci. Res. Program Bull. 10, 1 (1972)].

15. In Broadbent's formulation (13), a response set alters the decision criterion for recognition of the selected target. The proposed relation between $\mathrm{P}_{3}$ and response set is therefore sup ported by reports that $\mathrm{P}_{3}$ amplitude is closely correlated with decision criterion during hreshold detection tasks [D. Paul and S Sutton, Science 177, 362 (1972); K. C. Squires, S. A. Hillyard, P. Lindsay, Percept. Psychophys., in press], and with signal likelihood (7). At present it is difficult to determine whether $\mathrm{P}_{3}$ is a sign of the actual perceptual recognition process, the subsequent response activation, or of a concomitant nonspecific arousal or motivational event.

16. Supported by NASA grant No. NGR 05-009198 and NIH grant No. USPHS NS 10482-01 awarded to Robert Galambos and by the Sloan Foundation.

8 June 1973 which may refiect post-recognition processes

13. D E Broadbent, in Attention: Contemporary

Magid's comment conveys the impression that we have postulated a new mechanism of intraaxonal transport. In our report we described the transport of putrescine within the optic nerve, but did not speculate on the mechanism. Diffusion itself is also a transport phenomenon. Whether the described putrescine transport occurs by diffusion or any other transport mechanism cannot be concluded from our results.

Using our published data Magid estimates a diffusion constant for putrescine within the axons and compares this constant with intracellular diffusion constants of small organic and metal ions comparable in molecular weight to putrescine. In principle this method is legitimate if one compares the diffusion constant of putrescine to the diffusion constants of other putrescine-like ions. For example, $\mathrm{Ca}^{2+}$ is one of the ions which has putrescine-like physiological and biochemical properties. Unfortunately, the diffusion coefficient for $\mathrm{Ca}^{2+}$ in nerves is not known, but it is known in muscle cells (1). In the case of muscle the diffusion coefficient is about 100 times smaller than in pure aqueous solution. There are good reasons to assume that chemical interactions of putrescine ions with the components of a nerve cell may further reduce putrescine mobility.

Numerous experiments involving axonal transport of protein with an incorporated labeled amino acid give evidence against simple diffusion as a transport mechanism. If protein synthesis in the perikaryon is inhibited by cycloheximide or puromycin in the presence of an unphysiologically high concentration of injected labeled amino acid, the transport of this labeled free amino acid is not seen. According to Magid's hypothesis one should see diffusion of these amino acids at a speed comparable to that of putrescine. Furthermore, in experiments with colchicine in the presence of excess amounts of labeled amino acids, transport of these amino acids is not seen. Should one suppose that simple diffusion can be stopped by colchicine?

H. A. FISCHER

Physiology and Biophysics, University of Washington, Seattle 98195

\section{References}

to account for the appearance of a specified fraction, $C_{x} / C_{0}$, of the original concentration at a point down the nerve.

If one could detect 1 percent, then a substance whose diffusion constant was as low as $3 \times 10^{-8} \mathrm{~cm}^{2} \mathrm{sec}^{-1}$ could be detected. Although it is difficult to determine precisely from the
1. H. A. Fischer and E. Schmatolla, Science 176, 1327 (1972)

2. H. S. Carslaw and J. C. Jaeger, Conduction of Heat in Solids (Oxford Univ. Press, London, 1959), p. 63.

3. E. Koppenhoefer and W. Vogel, Pfluegers Arch. Gesamte Physiol. Menschen Tiere 313, 361 (1969).

4. M. J. Kushmerick and R. J. Podolsky, Science 166, 1297 (1969).

12 March 1973; revised 11 June 1973
H. A. Fisc
ch Group,

Neurochemical Research Group,
Max Planck Institute for Brain

Research, Frankfurt/M., Germany

E. Schmatolla

Neuropathology Division, Max Planck Institute for Brain Research

Reference

1. M. J. Kushmerick and R. J. Podolsky, Sci-

16 August 1973 ence 166, 1297 (1969). 
http://www.jstor.org

\title{
LINKED CITATIONS
}

- Page 1 of 2 -

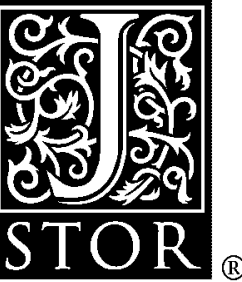

You have printed the following article:

Electrical Signs of Selective Attention in the Human Brain

Steven A. Hillyard; Robert F. Hink; Vincent L. Schwent; Terence W. Picton

Science, New Series, Vol. 182, No. 4108. (Oct. 12, 1973), pp. 177-180.

Stable URL:

http://links.jstor.org/sici?sici=0036-8075\%2819731012\%293\%3A182\%3A4108\%3C177\%3AESOSAI\%3E2.0.CO\%3B2-3

This article references the following linked citations. If you are trying to access articles from an off-campus location, you may be required to first logon via your library web site to access JSTOR. Please visit your library's website or contact a librarian to learn about options for remote access to JSTOR.

\section{References and Notes}

\author{
${ }^{3}$ Enhancement of Evoked Cortical Potentials in Humans Related to a Task Requiring a \\ Decision \\ Hallowell Davis \\ Science, New Series, Vol. 145, No. 3628. (Jul. 10, 1964), pp. 182-183. \\ Stable URL: \\ http://links.jstor.org/sici?sici=0036-8075\%2819640710\%293\%3A145\%3A3628\%3C182\%3AEOECPI\%3E2.0.CO\%3B2-V
}

${ }^{3}$ Selective Attentiveness and Cortical Evoked Responses to Visual and Auditory Stimuli Paul Spong; Manfred Haider; Donald B. Lindsley

Science, New Series, Vol. 148, No. 3668. (Apr. 16, 1965), pp. 395-397.

Stable URL:

http://links.jstor.org/sici?sici=0036-8075\%2819650416\%293\%3A148\%3A3668\%3C395\%3ASAACER\%3E2.0.CO\%3B2-6

\footnotetext{
${ }^{3}$ Human Auditory Attention: A Central or Peripheral Process?

Terence W. Picton; Steven A. Hillyard; Robert Galambos; Maurice Schiff

Science, New Series, Vol. 173, No. 3994. (Jul. 23, 1971), pp. 351-353.

Stable URL:

http://links.jstor.org/sici?sici=0036-8075\%2819710723\%293\%3A173\%3A3994\%3C351\%3AHAAACO\%3E2.0.CO\%3B2-R
}

\footnotetext{
${ }^{6}$ Evoked Potential Correlates of Signal Recognition between and within Modalities

Judith M. Ford; Walton T. Roth; Stanley J. Dirks; Bert S. Kopell

Science, New Series, Vol. 181, No. 4098. (Aug. 3, 1973), pp. 465-466.

Stable URL:

http://links.jstor.org/sici?sici=0036-8075\%2819730803\%293\%3A181\%3A4098\%3C465\%3AEPCOSR\%3E2.0.CO\%3B2-J
}

NOTE: The reference numbering from the original has been maintained in this citation list. 
http://www.jstor.org

\section{LINKED CITATIONS \\ - Page 2 of 2 -}

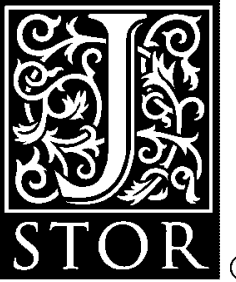

\section{${ }^{15}$ Evoked Potential Correlates of Response Criterion in Auditory Signal Detection Dina Doré Paul; Samuel Sutton}

Science, New Series, Vol. 177, No. 4046. (Jul. 28, 1972), pp. 362-364.

Stable URL:

http://links.jstor.org/sici?sici=0036-8075\%2819720728\%293\%3A177\%3A4046\%3C362\%3AEPCORC\%3E2.0.CO\%3B2-L

NOTE: The reference numbering from the original has been maintained in this citation list. 